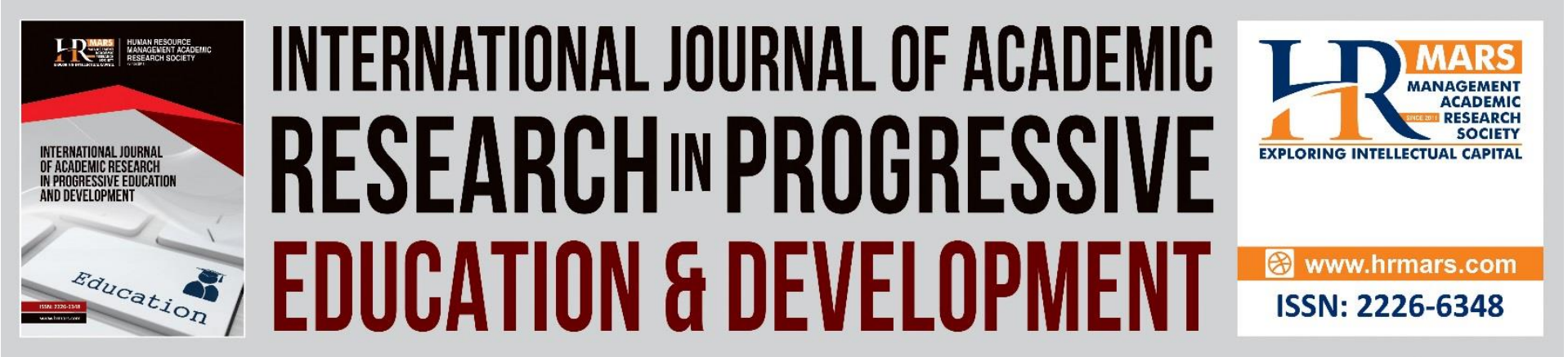

\title{
Issues and Barriers in the Execution of Precast Construction
}

\section{A. Othuman Mydin}

To Link this Article: http://dx.doi.org/10.6007/IJARPED/v11-i1/12074

DOI:10.6007/IJARPED/v11-i1/12074

Received: 14 November 2021, Revised: 18 December 2021, Accepted: 07 January 2022

Published Online: 29 January 2022

In-Text Citation: (Mydin, 2022)

To Cite this Article: Mydin, M. A. O. (2022). Issues and Barriers in the Execution of Precast Construction. International Journal of Academic Research in Progressive Education and Development, 11(1), 448-454.

\section{Copyright: (C) 2022 The Author(s)}

Published by Human Resource Management Academic Research Society (www.hrmars.com)

This article is published under the Creative Commons Attribution (CC BY 4.0) license. Anyone may reproduce, distribute, translate and create derivative works of this article (for both commercial and non-commercial purposes), subject to full attribution to the original publication and authors. The full terms of this license may be seen

at: $\underline{\text { http://creativecommons.org/licences/by/4.0/legalcode }}$

Vol. 11(1) 2022, Pg. $448-454$

Full Terms \& Conditions of access and use can be found at http://hrmars.com/index.php/pages/detail/publication-ethics 


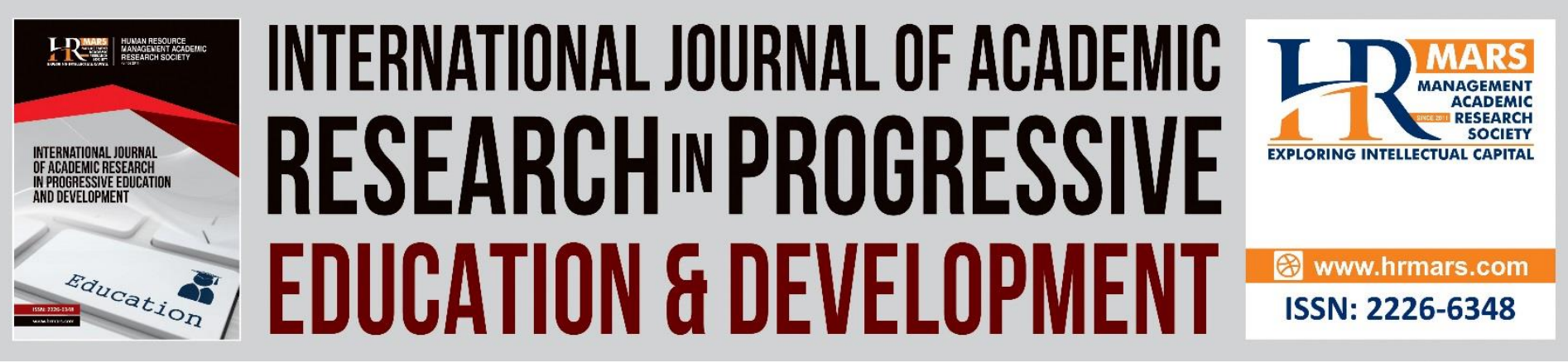

\title{
Issues and Barriers in the Execution of Precast Construction
}

\author{
M. A. Othuman Mydin \\ School of Housing, Building and Planning, Universiti Sains Malaysia, 11800, Penang, Malaysia \\ Corresponding Author Email: azree@usm.my
}

\begin{abstract}
The construction industry in Malaysia is experiencing a transformation from conventional methods to a more systematic and mechanized method known as prefab system. Each state in Malaysia is currently examining the developments of the prefab system and its potential to overcome the shortages of housing accommodations in this country. Though, there are unsettled matters evolving from the continuing and widespread adoption of the traditional method of construction. Among them are the subsequent disintegration of the industry itself; slowdown in production and delivery time; superfluous surpluses and shortage of sustainability routine. The Malaysian government, involved through its agency, the Construction Industry Development Board (CIDB) has been persistently pushing the construction industry to utilize of the prefab method of construction since the year 2003. It is a part of an incorporated endeavour to further improve the aptitude, potential, effectiveness, and competitiveness of the industry as well as to diminish the industry's dependence on foreign labours. This is also an attempt in the Malaysian construction industry to encourage positive inroads in matters related to construction-site safety with regards to a working environment which is cleaner, more convenient, and more organized. This production is also mentioned as being able to provide more protection to the environment as it secures the sustainability of the industry. This paper will discuss on some current matters related to the execution of prefab system and main barriers towards success of this construction type in Malaysia.
\end{abstract}

Keywords: Precast, IBS, Concrete, Prefabrication, Block, Construction

\section{Introduction}

Despite its history in Malaysia, the usage of prefab in buildings in Malaysia is still low compared to developed countries such as Europe, United States and Japan. The Construction Industry Development Board (CIDB) Malaysia conducted a survey from which they discovered that the level of usage of the prefab system in the local construction industry is at $15 \%$ based on the prefab system Survey in 2003 (Akin, 2001). The main barriers that impede the growth of prefab system are the resistance from the parties involved in the construction and the local authorities who are generally unwilling to make changes in local building regulations. Moreover, the subcontractors who rely on labour will be out of business due to the fact that prefabrication will reduce the number of workers, as this method is heavily-dependent on machines. However, the Malaysian construction industry needs to evolve in-line with this 


\section{DEVELOPMENT}

Vol. 11, No. 1, 2022, E-ISSN: 2226-6348 @ 2022 HRMARS

globalised era and prepare itself for an industry where an increase in productivity, quality and safety is a must (Abedi et al., 2011). It seems that examples of successful implementations of such an established manufacturing process have not been fully appreciated by the local construction industry.

Figure 1 shows the IBS milestone in Malaysia from 1999 to 2015.

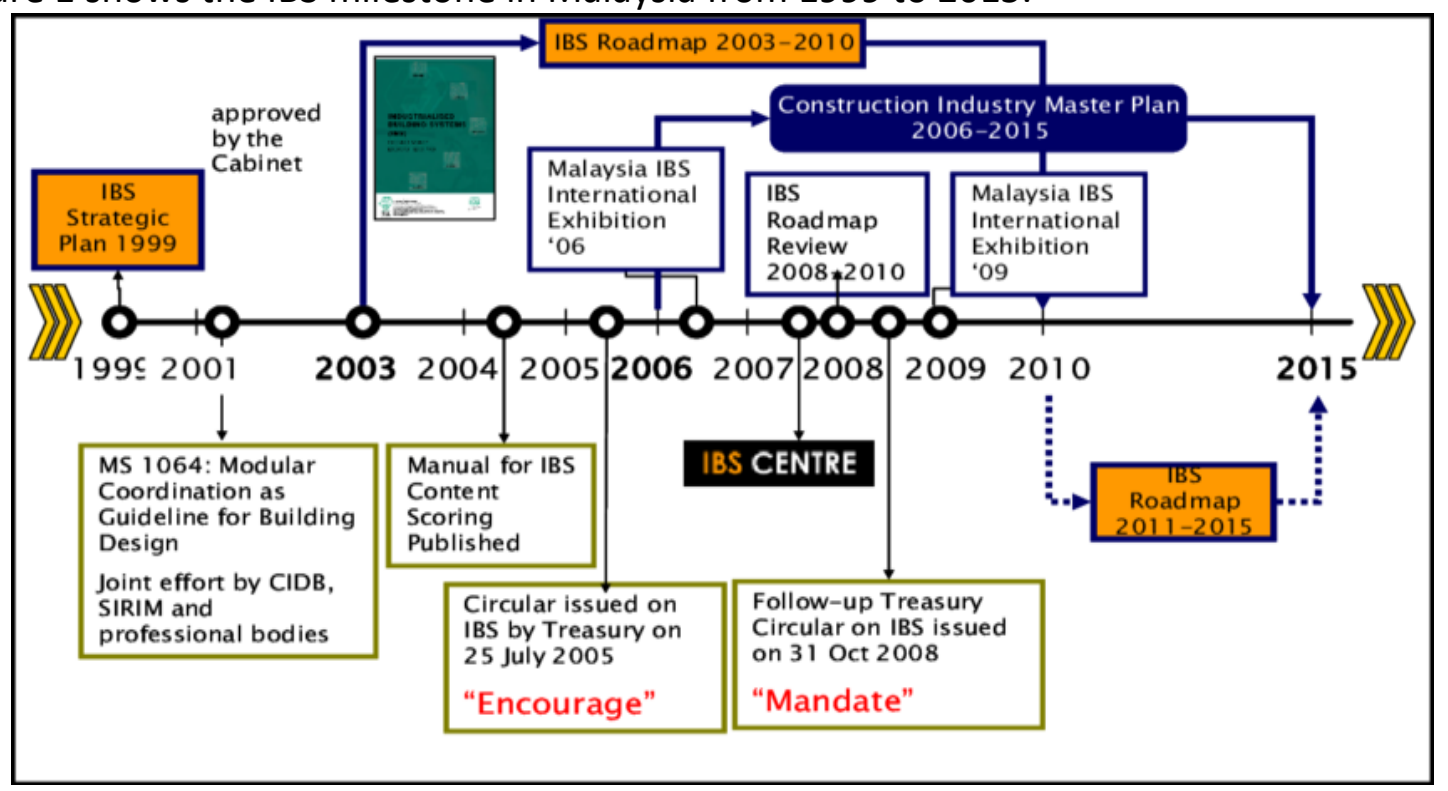

Figure 1: IBS milestone in Malaysia

Maybe a greater intervention from government linked companies (GLCs) is needed to set up the mega housing projects and to provide an end-less supply of ready-made components for buildings by multiple vendors and sup-pliers (Cuff, 1991). The potential for prefab sector in Malaysia is enormous to say the least. The conservative estimate of the industry is approximately to RM2 billion, making the future of the industry secure. Having to recognize the potential of the industry, the Government of Malaysia has implemented the roadmap for the development of prefab system in Malaysia three years ago. Among the key goals of the roadmap are, to reduce the number of foreign workers in the construction sector from $75 \%$ in 2005 to $15 \%$ in 2009 through prefab sector, to utilize this system in government building projects by up to $70 \%$ by 2008 and finally to achieve full industrialization by 2010 . 
Figure 2 demonstrates the development of IBS in Malaysia.

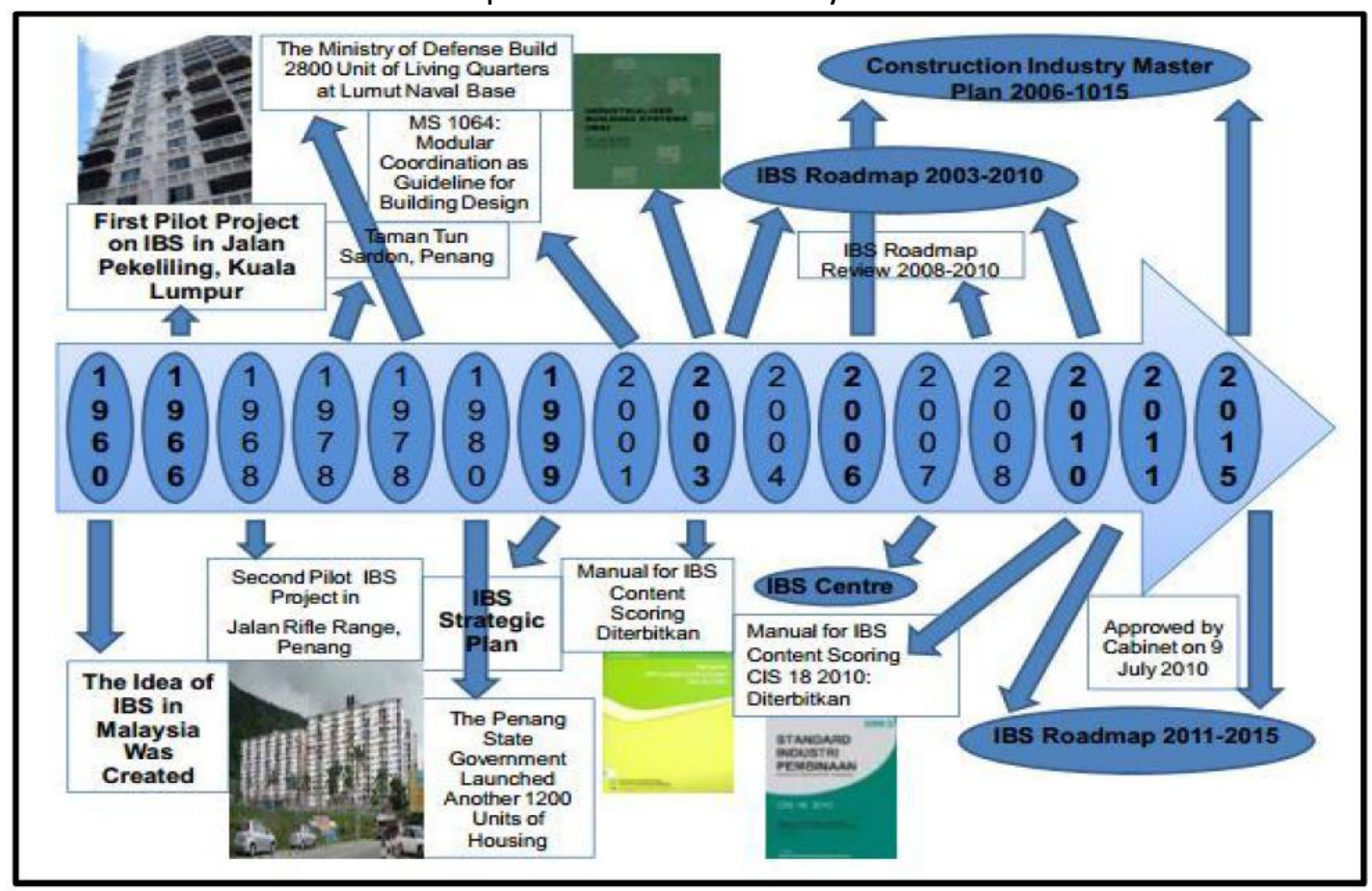

Figure 2: Development of IBS in Malaysia [2]

To achieve these goals, a more structured approach must be taken in implementing prefab system. Dishing out contracts haphazardly and hoping that the industry will build itself is a serious error of judgment. This structured approach forms a pyramid, with the bottom layer supporting the upper layers. At the bottom of the pyramid are the small components and accessories suppliers. This forms the largest group, consisting of many small and medium scale industries manufacturing items such as windows, doors, grills and frames etc. This group supports the medium sized and manufactured components group. Smaller than the small components groups, the medium components group is responsible for the sub-assembly of components and individual structure components. This group in turn supports the large component group, which manufactures precast concrete and steel frames as well as the modules. Finally, at the top of the pyramid is the developer, responsible for assembling the building. The creation of a structured system such as the pyramid, enables companies to easily identify which step of the prefab construction process they fall under, who they can sell their products to and who they can buy their components from.

\section{Difficulties Related to Precast System}

The most widely-used form of prefab in building and civil engineering is the use of prefab concrete and prefab steel sections in structures where a particular part or form is repeated many times. It can be difficult to construct the formwork required to mould concrete components on site and delivering wet concrete to the site before it starts to set requires precise time management. Pouring concrete sections in a factory brings the advantages of being able to re-use moulds and the concrete can be mixed on the spot without having to be transported to and pumped wet on a congested construction site (Edwards, 1999). Prefabricating steel sections reduces on-site cutting and welding costs as well as the associated hazards. 
Prefabrication techniques are used in the construction of apartment blocks, and housing developments with repeated housing units. The quality of prefabricated housing units had increased to the point that they may not be distinguish-able from traditionally-built units to those that live in them. The technique is also used in office blocks, warehouses, and factory buildings. Prefabricated steel and glass sections are widely used for the exterior of large buildings (Holm, 2006).

Detached houses, cottages, log cabin, saunas, etc. are also sold with prefabricated elements. Prefabrication of modular wall elements allows building of complex thermal insulation, window frame components, etc. on an assembly line, which tends to improve quality over onsite construction of each individual wall or frame. Wood construction in particular benefits from the improved quality. However, tradition often favours building by hand in many countries, and the image of prefab as a "cheap" method only slows its adoption. However, current practice already allows the modifying the floor plan according to the customer's requirements and select-ing the surfacing material, e.g., a personalized brick facade can be fabricated even if the load-supporting elements are timber (Porter, 2000).

Prefabrication saves engineering time on the construction site in civil engineer-ing projects. This can be vital to the success of projects such as bridges and avalanche galleries, where weather conditions may only allow brief periods of construction. Prefabricated bridge elements and systems offer bridge designers and contractors significant advantages in terms of construction time, safety, environ-mental impact, constructability, and cost. Prefabrication can also help minimize the impact on traffic from bridge building. Additionally, small, commonly-used structures such as concrete pylons are in most cases prefabricated.

Radio towers for mobile phone and other services often consist of multiple prefabricated sections. Modern lattice towers and guyed masts are also commonly assembled of prefabricated elements. Prefabrication has become extensively used in the assembly of aircraft and spacecraft, with components such as wings and fuselage sections often being manufactured in different countries or states from the final assembly site. However, this is sometimes for political rather than commercial reasons.

\section{Issues and Barriers in The Execution of Precast System}

Even though the prefab system has been in existence for a long time but there are still many unresolved issues. One of the prefab system issues is the ability of the industry players to equip with necessary technical knowledge in order to adopt prefab system in their project. Below are some more issues regarding prefab system implement in Malaysia (Purcell and Gero, 1996).

One of the issues is prefab system as mass construction method. People often misinterpreted prefab system term by relate it with industrialized building that was built in 1960s. Prefabricated mass construction method, low quality billing leakages, abandoned projects, unpleasant architectural appearances, and other drawback all these issues were normally associated with industrialized building. Public gave a bad impression about precast concrete because of poor architectural design (Spector, 2001). There several cases in Malaysia regarding the uses of prefab system had led to such drawbacks. One of the cases is Pekeliling flats in Taman Tun Sardon, Gelugor, Penang. This flat was pre-fabricated flats, and it has been built for lower income group. To ensure the cost accommodation is low, this flat was constructed in mass. Design of this flats was very basic and not considering the aspect of serviceability. 
Due to lacking in design, the precast building going through some problem such as leakage and leakage has become the most common issue with precast building. Usually, low-cost housings are not maintained properly, thus it gives a bad impressions and poor image of prefab system buildings. Barriers: Execution prefab system in Malaysia has not been making headways as anticipated even though the government has an early effort to promote usage of prefab system as an alternative traditional and labour-intensive construction method. Some researchers have investigated and identifies a number of barriers to the effective implementation of prefab system in Malaysia. Based on the researcher information, basically the barriers to the prefab system in Malaysia can be summarized into five main area which is cost and finance, skills and knowledge, project delivery and supply chain, perception of clients and professional and lastly the lack government incentives, directives, and promotion. These barriers need to be solved if not it can affect the various stakeholders in the prefab system. This will be a very hard situation for new local companies to enter the prefab system business since it needs extra capital investment.

That is why conventional labour-intensive method become their choice rather than prefab system. This situation also closed the chance for a new company to compete for opportunities with international competitors that are stronger in terms of financial capability, technology, or specialization. Adopting a new system means that there need to be substantial and sustained budget, allocated time for training of human resources and specialized equipment and machineries. Lack of superior equipment and machineries proves to be a major hurdle that hinders works in prefab system -based projects. Moreover, the lack of research and development (R\&D) facilities has made the local contractors to depends very much on foreign expertise and technology. Other than that, all the material and machineries are imported from the developer countries, and this will require a lot of cost to producing the prefab system component (Visser, 2008).

\section{Conclusion}

The prefab system proved to be a success. Not only it was efficient in accelerating the construction of housing projects, but it also improved the quality and affordability of the projects in which the IBS was deployed. Based on different reference materials accepted by authorities in the construction fraternity, we have several ways of defining the prefab system. Despite the prefab system being well-known and accepted by most construction firms due to its theoretical advantage in terms of speed, safety and quality, wet construction method is still widely regarded in Malaysia as a conventional and safe option regardless of incurring higher costs and slower production rates The increasing demands of clients in the construction industry have led to the selection of a faster and cheaper construction method which, by the way, is capable of producing higher quality results. For that reason, builders involved in the construction sector are required to decide either to utilize the prefab system or the traditional method of construction.

Even though cost was revealed among the precast construction barrier element, but it is hardly be stated as the main reason behind the denial to implement precast construction. Conventional construction methods are preferred rather than proposing precast system since shifting the building system from a conventional approach to precast construction is not motivated by cost factors. Another reason that adds to this belief is the fact that construction firms have been exposed and trained in the conventional construction method for decades and there is an abundance of cheap foreign workers in Malaysia. Shifting to IBS seems to be too complicated unless the Government imposes a policy or strict legislative requirement on 


\section{DEVELOPMENT}

Vol. 11, No. 1, 2022, E-ISSN: 2226-6348 ㄷ 2022 HRMARS

the use of precast system or redefines the market by setting a mandatory quota for precast projects.

Consequently, a long-term comprehensive policy and directive statement towards the industrialization of the building and construction sector should be pursued by the Government in order to shape the future of the Malaysian construction industry. Further, developing a precast system research and development centre, providing comprehensive training packages, and introducing certification of precast component vendors are some of the subjects that the Government needs to consider urgently in order to improve precast system implementation in the Malaysian construction sector.

\section{References}

Abedi, M., Fathi, M. S., \& Mirasa, A. K. (2011). Establishment and development of IBS in Malaysia. International Building and Infrastructure Technology Conference (BITECH 2011), 7 \& 8 Jun 2011, Penang, Malaysia.

Akin, O. (2001). Variants in design cognition in C Eastman, M McCracken and W Newsletter (eds) Design knowing and learning: cognition in design education, Elsevier Science, Amsterdam, pp: 105-124.

Cuff, D. (1991'0. Architecture: the story of practice. Cambridge, Mass, MIT Press. Cuff, D., 2000. Epilogue. In KOSTOF, S. (Ed.). The Architect: chapters in the history of the profession. Berkeley, Calif., University of California Press.

Edwards, E. H. (1999). The architect in the building process: pragmatic reflection, concrete experience. Stockholm, Royal Institute of Technology School of Architecture Surveying and Civil Engineeting.

Holm, I. (2006). Ideas and Beliefs in Architecture and Industrial design, (unpublished).ISSN 1502- 217X Phd Thesis, Oslo School of architecture and design, University of Oslo.

Porter, D. (2000). Why do architects wear black? Thinking beyond the trap. In TOFT, A. E. (Ed.) Ethics in architecture: architectural education in the epoch of virtuality. [Leuven], European Association for Architectural Education.

Purcell, T., \& Gero, J. S. (1996). Design and other types of fixation, Design Studies, 17(4): 363383.

Spector, T. (2001). The ethical architect: the dilemma of contemporary practice. New York, Princeton Architectural Press.

Visser, W. (2008). Design: one, but in different forms 2008 Elsevier Ltd. Available at: http://www.sciencedirect.com 